\title{
REVIEW
}

\section{Impact of exacerbations on COPD}

\section{A. Anzueto}

\begin{abstract}
Exacerbations of chronic obstructive pulmonary disease (COPD) determine diseaseassociated morbidity, mortality, resource burden and healthcare costs. Acute exacerbation care requirements range from unscheduled primary care visits to emergency room, inpatient or intensive care, generating significant costs in COPD. Even after an exacerbation resolves, respiratory, physical, social and emotional impairment may persist for prolonged time. Frequent exacerbations, mainly in patients with severe COPD, accelerate disease progression and mortality. Thus, patients with frequent exacerbations have a more rapid decline in lung function, worse quality of life and decreased exercise performance. Management of COPD directed to reduce incidence and severity of exacerbations improves long-term health status and conserves health care resources and costs.
\end{abstract}

KEYWORDS: Acute exacerbations, chronic obstructive pulmonary disease, pulmonary function, quality of life

hronic obstructive pulmonary disease (COPD) affects a large number of patients and is associated with significant morbidity, disability and mortality $[1,2]$. COPD is complicated by frequent and recurrent acute exacerbations, which result in enormous healthcare expenditures and high morbidity. An exacerbation of COPD is defined as "an event in the natural course of the disease characterized by a change in the patient's baseline dyspnea, cough, and/or sputum and beyond normal day-today variations, that is acute in onset and may warrant a change in regular medication in a patient with underlying COPD" $[3,4]$. Exacerbations are categorised in terms of either clinical presentation (number of symptoms) or utilisation of heathcare resources $[3,4]$.

Exacerbations of COPD are estimated to result in $\sim 110,000$ deaths and more than 500,000 hospitalisations per year, with over $\$ 18$ billion spent in direct costs annually [1, 2]. In addition to the financial burden required to care for these patients, other "costs", such as days missed from work and severe limitations in quality of life, are important features of this condition $[5,6]$.

Exacerbations are a significant component of the clinical course in COPD [7]. Furthermore, as COPD progresses, exacerbations become more frequent [3, 8-14]. DONALDSON et al. [11] reported that patients with severe COPD (Global Initiative for Chronic Obstructive Lung Disease (GOLD) category III) had an annual exacerbation frequency of 3.43 events per year compared with 2.68 per year for those with moderate COPD (GOLD category II; $p=0.029)$. PAGGIARO et al. [10] reported, in patients with forced expiratory volume (FEV1) $>60 \%$ predicted, $1.6 \pm 1.5$ exacerbations per year (mean $\pm \mathrm{SD})$, compared with $1.9 \pm 1.8$ exacerbations in patients with FEV1 $59 \%-40 \%$ pred, and $2.3 \pm 1.9$ exacerbations in patients with $\mathrm{FEV} 1<40 \%$ pred $[10,11]$. Other studies showed that patients who suffer a high number of exacerbations will continue to have frequent episodes [14]. Recent large prospective clinical studies have shown that COPD patients in GOLD category II (FEV1 50-80\% pred) also have a significant number of exacerbations that can be reduced with pharmacotherapy $[15,16]$. Thus, patients with more severe COPD are going to have frequent exacerbations, but it is also important to point out that patients with more moderate disease also develop a significant number of these events (table 1).

\section{IMPACT OF EXACERBATIONS ON SYSTEMIC INFLAMMATION AND COMORBIDITIES}

Although respiratory infections are assumed to be the main risk factors for exacerbation of COPD, other conditions, including industrial pollutants, allergens, sedatives, congestive heart failure and pulmonary embolism, have been identified $[3,4,19,20]$. The cause of an exacerbation of COPD may be multifactorial, so that viral infection or levels of air pollution may exacerbate the existing inflammation in the
CORRESPONDENCE

A. Anzueto

(111E) Pulmonary/critical care 7400 Merton Minter Boulevard San Antonio

Texas

78229 USA

E-mail: anzueto@uthscsa.edu

Received:

March 162010

Accepted after revision:

April 042010

PROVENANCE

Publication of this peer-reviewed article was supported by Dompé SPA, Italy (unrestricted grant,

European Respiratory Review issue 116) 


\begin{tabular}{|c|c|}
\hline TABLE 1 & $\begin{array}{l}\text { Risk factors for frequent exacerbations (more than } \\
\text { two per year) in patients with chronic obstructive } \\
\text { pulmonary disease }\end{array}$ \\
\hline \multicolumn{2}{|l|}{ Risk factors } \\
\hline \multicolumn{2}{|c|}{ Increased age } \\
\hline \multicolumn{2}{|c|}{ Severity of $F E V_{1}$ impairment } \\
\hline \multicolumn{2}{|c|}{ Chronic bronchial mucus hypersecretion } \\
\hline \multicolumn{2}{|c|}{ Frequent past exacerbations } \\
\hline \multicolumn{2}{|c|}{ Daily cough and wheeze } \\
\hline \multicolumn{2}{|c|}{ Persistent symptoms of chronic bronchitis } \\
\hline \multicolumn{2}{|c|}{ Comorbid conditions: mainly cardiovascular disease } \\
\hline
\end{tabular}

airways, which in turn may predispose to secondary bacterial infections. COPD patients have frequent comorbid conditions, particularly coexistent cardiac disease, hypertension, diabetes, etc. [3]. Coexistent cardiac disease has been shown to be a risk factor for increased hospital admission [21, 22] and mortality in patients with COPD exacerbation [23, 24]. Furthermore, ischaemic heart disease and/or congestive heart failure were reported to increase the rate of treatment failure, thus contributing to the worsening of the patients' condition [21, 22]. However, in a hospital-based study, very severe COPD patients (FEV1 $<35 \%$ pred and use of supplemental oxygen therapy) no association between cardiac comorbidity and outcome was found [24]. The results suggest that cardiac comorbidity is a risk factor of poor outcome, particularly in moderate-severe COPD patients; however, when lung disease is severe, impairment in pulmonary function prevails over cardiac disease. Additionally, older patients who also have more severe comorbid conditions appear to be at risk for severe life-threatening exacerbations that may result in hospital admission and even death [8, 24, 25].

Several studies have shown that COPD patients have higher levels of some inflammatory markers in blood, mainly Creactive protein (CRP) [26], fibrinogen [27] and inflammatory cytokines [28]. EAGAN et al. [29] assessed the systemic levels of six inflammatory mediators in a large cohort of COPD patients and controls. These investigators confirmed that certain circulating inflammatory mediators are affected in COPD. COPD confounded variables, such as sex, age, smoking status, disease severity, comorbid conditions, etc., were controlled. These investigators demonstrated that COPD patients were more likely to have significantly decreased blood levels of osteoprotegrin and higher levels of CRP. They were also able to identify that soluble tumour necrosis factor receptor- 1 and osteoprotegrin changes were related to disease severity, based on GOLD stage and frequency of exacerbations. Furthermore, recent reports have shown that using anti-inflammatory medications, such as statins, significantly impact the rate of lung function decline, and their use prior to exacerbations is associated with significant decreases in mortality [30]. Therefore, exacerbations are likely to be present in patients with comorbid conditions and result in a significant inflammatory burden. Further prospective studies are needed to validate these clinical studies.

\section{IMPACT OF EXACERBATIONS ON LUNG FUNCTION}

Some investigators believe that more frequent exacerbations are associated with more rapid decline of FEV1 [31]. DONALDSON et al. [11] reported a mean of 2.92 exacerbations per year in COPD patients with moderate to very severe disease (mean FEV1 38\% pred). The mean rate of decline in FEV1 in the total cohort was $36 \mathrm{~mL} \cdot \mathrm{yr}^{-1}$, but was greater in patients with more exacerbations $\left(40.1 \mathrm{~mL} \cdot \mathrm{yr}^{-1}\right.$ versus $32.1 \mathrm{~mL} \cdot \mathrm{yr}^{-1}$, respectively; $\left.\mathrm{p}<0.05\right)$. Frequent exacerbations (more than two per year) have been associated with increased dyspnoea and reduced exercise capacity [11, 16], greater decline in health status $[32,33]$ and increased likelihood of becoming housebound [11,34]. More recently, CeLLI et al. [35] reported the impact of frequent exacerbations on the decline in FEV1 in data from the Toward a Revolution in COPD Health (TORCH) study, in which patients experiencing greater frequency of exacerbations during the 3-yr study period had a faster decline in FEV1.

It seems logical that repeated episodes of COPD exacerbations may potentially impair lung tissues and lead to an accelerated rate of decline in pulmonary function. This concept is supported by a number of experimental observations. 1) Exacerbations are associated with transient decreases in pulmonary function that, in some cases, take weeks to return to baseline levels [36, 37]. 2) Patients suffering from recurrent exacerbations have been shown to have increased concentrations of inflammatory markers in sputum, even in stable phase, which suggests persistent inflammation and potential lung damage [38]. 3) Neutrophils are attracted into the airway lumen during exacerbations [39]. In fact, increased levels of neutrophils in sputum correlated with rapid decline in FEV1 in a 15-yr follow-up study [40]. There are recent reports that have identified a significantly increased number of eosinophils in patients with COPD exacerbation [41, 42]. The significance of these findings is not fully understood. 4) In cross-sectional studies, higher bacterial load in respiratory secretions have been associated with increased inflammation and decreased lung function [43]. 5) The urinary excretion of desmosine and isodesmosine, products of degradation of lung elastine, are significantly increased during exacerbations of COPD compared with stable phase [44], coinciding with an increase in free elastase during exacerbations $[38,45]$; furthermore, higher urinary concentrations of desmosine have been associated with faster decline in FEV1 in COPD [46]. 6) A correlation has been found between the number of previous exacerbations and the extent of emphysematous changes seen by computed tomography scan [17].

\section{IMPACT OF EXACERBATIONS ON HEALTH-RELATED QUALITY OF LIFE}

Exacerbations have been shown to dramatically impair the feeling of wellbeing in COPD patients. Differences in scores in health-related quality of life (HRQoL) questionnaires between the stable phase and the exacerbation are very important in magnitude. A group of patients with COPD exacerbation showed a moderate-to-large improvement in all four domains of the Chronic Respiratory Disease Questionnaire after 10 days of treatment [18]. This improvement was not observed in patients who relapsed after treatment of exacerbation. 
A study by CONNORS JR et al. [36] reported the quality of life outcomes in patients hospitalised with acute exacerbations of COPD. At 6 months, $54 \%$ of patients required assistance with at least one activity of daily living and $49 \%$ considered their health status to be fair or poor. No analysis was conducted on the relationship between readmissions and perceived quality of life. The recovery of HRQoL parameters after an acute COPD exacerbation may be determined by several factors. SPENCER et al. [33] in exacerbated patients who did not relapse during follow-up experienced an improvement in the St George's Respiratory Questionnaire (SGRQ) of 11.8 units at 1 month and 17 units after 5 months of the onset of the exacerbation. These results indicate that the recovery of health status after an exacerbation may take longer than previously expected. In contrast, median recovery time for lung function after an exacerbation is 6 days and for symptoms is 7 days [33]. However, this recovery may be influenced by the severity of the exacerbation. The more severe the exacerbation, the longer it takes to recover. SEEMUNGAL et al. [37] showed that only $75 \%$ of patients return to their baseline peak flow values 35 days after the episode. The SGRQ and Medical Research Council questionnaire were completed by patients at the end of the study. Exacerbations were more frequent in patients with frequent previous exacerbations (OR 5.5, $\mathrm{p}=0.001$ ). Using the median number of exacerbations, patients were classified as infrequent exacerbators (0-2) or frequent exacerbators (3-8). SGRQ total score was significantly worse in frequent exacerbators (mean difference 14.8; $\mathrm{p}<0.001$ ) (fig. 1).

In multiple regression analyses, exacerbation frequency was strongly correlated with SGRQ total score and component scores. MiRAVITLLES et al. [6] confirmed the impact of exacerbations on health status. Thus, these studies showed that patients who suffered more exacerbations had significantly worse SGRQ scores compared with infrequent exacerbators, and HRQoL-related questionnaires offer complementary information to lung function and respiratory symptoms to monitor the course of recovery of an exacerbation. The slow recovery of HRQoL after an exacerbation suggests that these patients will not return to their baseline condition and will experience further deterioration of their quality of life over time.

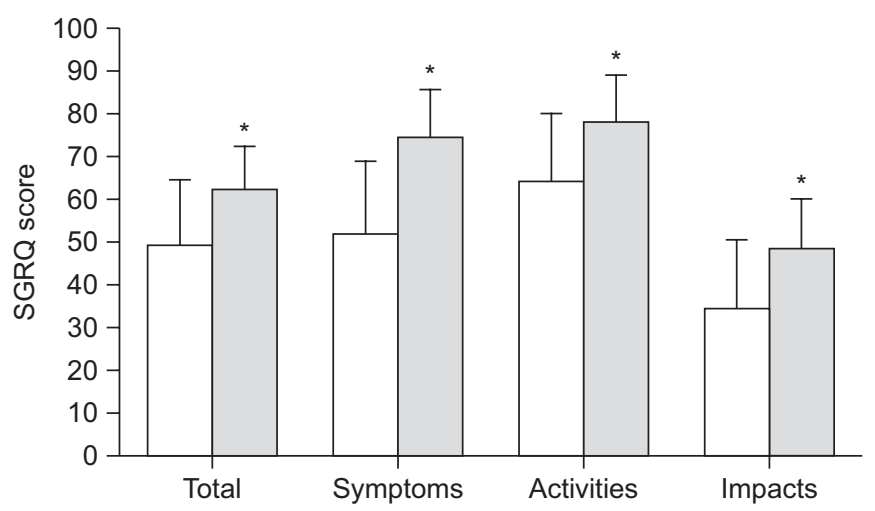

FIGURE 1. Relationship between exacerbation frequency and quality of life parameters. $\square$ : 0-2 exacerbations per year; $\square$ : 3-8 exacerbations per year. SGRQ: St George's Respiratory Questionnaire. *: $p<0.05$. Reproduced from [37] with permission from the publisher.
Furthermore, a patient's therapy during the exacerbation may influence outcome. ANDERSSON et al. [47] showed that patients who received long-term oxygen therapy had an improvement of the SGRQ scores by a mean of 14 units after 3 months; in contrast, those who did not receive oxygen showed a change of 9 units.

Unreported exacerbations are common and their long-term impact on HRQoL has been identified. Previous studies have shown that at least half of all COPD exacerbations identified by symptom worsening were not medically reported and therefore left untreated. SEEMUNGAL et al. [48] demonstrated that unreported exacerbations had similar characteristics to the reported ones. These exacerbations are associated with worsening symptoms worsening when they remain untreated. The short- and long-term impacts of unreported exacerbations on HRLQ were recently reported by $\mathrm{X}_{\mathrm{U}}$ et al. [49]. In a multicentre prospective cohort of 491 COPD patients, these investigators demonstrated that more than one unreported exacerbation was associated with significant worsening of the SGRQ score, and HRQoL at 1 yr after adjusting for known confounders. These data suggest that unreported exacerbations may have important long-term impact on patients, and there is an urgent need to develop tools that emphasise early recognition of exacerbations.

\section{IMPACT OF EXACERBATIONS ON EXERCISE PERFORMANCE}

COPD exacerbations not only impair both the short- and longterm quality of life, but also produce significant reduction in physical activity [50]. In order to understand how exacerbations actual impaired patients, HAUGHNEY et al. [51] reported a study that used actual patients' relative value judgment with discrete choice modelling techniques. These investigators demonstrated that exacerbations significant impact daily activities and level of medical care. For patients, the main impact of exacerbation on daily life is being housebound, more so than the actual symptoms. Other studies have also shown that exacerbations will not only impact physical activity but also physiological wellbeing [52]. These and future studies are needed to develop strategies in the prevention and management of COPD.

Loss of skeletal muscle has long been established as a feature of stable COPD. COPD patients have decreased quadriceps strength and fat-free mass [53]. These effects are worse after acute exacerbations. These effects may be more pronounced if we take into consideration that these patients received high doses of corticosteroids during an exacerbation. Further data related to the impact of exacerbation on exercise activity is the work by DONALDSON et al. [34]. In a longitudinal study, these investigators quantified time spent outdoors, and found that frequent exacerbators had spent less time. These investigators identified decreased activity a few days prior to exacerbations, which remained decreased for up to 5 weeks. More recent studies have utilised ambulatory activity monitoring. PITTA et al. [54] confirmed prior reports, and also described decreased activity level in patients that have exacerbations compared with those who did not. Furthermore, a decreased activity level 1 month after an exacerbation was associated with increased risk for hospitalisation. Thus, the investigators concluded that exacerbations decreased the overall exercise tolerance. 
More recently, the effect of exacerbations on the body mass, obstruction, dyspnoea and exercise capacity (BODE) index were reported [55]. The BODE index significantly decreases with an exacerbation and these effects remain over time. Most of the effect is due to significantly decreased exercise tolerance, manifested as decreased distance in 6-min walk test. Thus, exacerbations also impact upon exercise tolerance.

\section{ECONOMIC IMPACT OF EXACERBATIONS}

A further consequence of acute exacerbations of COPD is the great economic burden associated with the medical care required for these patients. Exacerbations are the largest direct cost for the treatment of COPD $[5,6,56,57]$. The major component was hospitalisations, which represented $58 \%$ of the total cost, followed by the medication acquisition cost of $32.2 \%$ [5].

\section{IMPACT OF EXACERBATIONS ON MORTALITY}

Clinical studies have reported a high mortality rate in patients admitted to the hospital with an acute exacerbation of COPD [36, 58-61]. Several studies have identified the risk factors associated with increased mortality. The Study to Understand Prognosis and Preferences for Outcomes and Rates of Treatment (SUPPORT) [36], which enrolled patients who had severe acute exacerbation of COPD, reported an in-hospital mortality rate of $11 \%$ in patients with acute hypercapnic respiratory failure. The 180-day mortality rate was 33\% and the 2-yr mortality rate was $49 \%$ (fig. 2). Predictors of mortality include acute physiology and chronic health evaluation (APACHE) III score, body mass index, age, functional status 2 weeks prior to admission, lower ratio of partial pressure (tension) of oxygen $\left(\mathrm{PO}_{2}\right)$ to fraction of inspired oxygen $\left(\mathrm{FI}, \mathrm{O}_{2}\right)$, congestive heart failure, level of serum albumin, cor pulmonale, lower activities of daily living scores and lower scores on the Duke Activity Status Index. This study also reported that only $25 \%$ of patients were both alive and able to report a good, very good, or excellent quality of life 6 months after discharge [36].

Several studies reported in-hospital mortality rate of $11-24 \%$ [38] and 22-35.6\% after 1 and 2 yrs, respectively [58, 59]. None of these studies have specifically examined the prognostic influence of acute exacerbation by itself. SOLER-CATALUNA et al. [61] were the first to report that severe exacerbations of COPD have

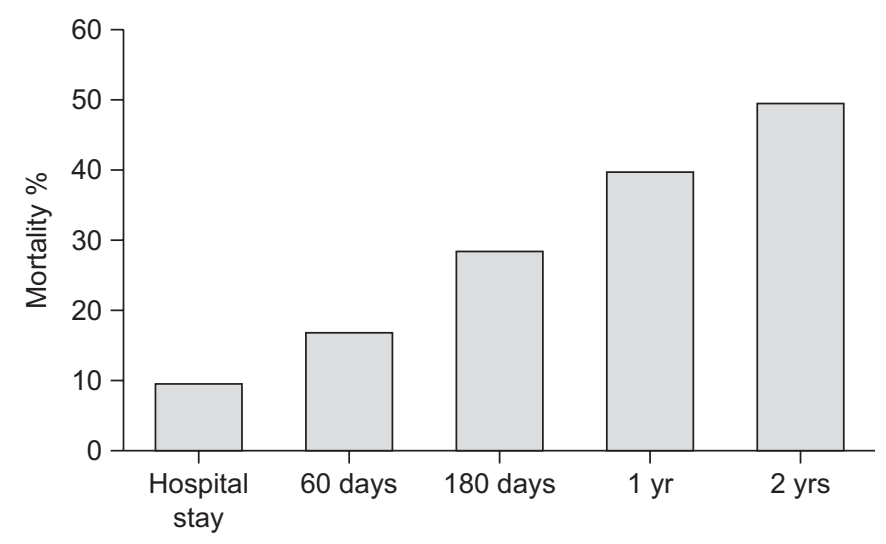

FIGURE 2. Mortality after chronic obstructive pulmonary disease exacerbation. Reproduced from [36] with permission from the publisher. an independent negative prognostic impact, with mortality increasing with the frequency of severe exacerbations and those requiring hospitalisation. Patients with frequent exacerbations had the highest mortality rate $(\mathrm{p}<0.001)$ with a risk of death 4.3 times greater (95\% CI 2.62-7.02) than for patients requiring no hospital management. Thus, exacerbation itself may be a significant factor associated with increased mortality in COPD, but the severity of the underlying disease may influence patient's outcome.

\section{PREVENTION/REDUCTION OF EXACERBATIONS}

The two most important preventive measures of COPD exacerbation are active immunisations, including influenza and pneumococcal vaccinations, and chronic maintenance pharmacotherapy [3, 4]. Currently, both annual influenza vaccination and polyvalent pneumococcal vaccine are recommended in patients with COPD $[3,4]$.

Recent clinical studies have demonstrated that chronic maintenance therapy in patients with COPD can significantly decrease the frequency of exacerbations. These studies show that long-active bronchodilators, including long-acting $\beta$ agonists (LABAs) (e.g. salmeterol and formoterol) [62]; and long-acting anticholinergics (e.g. tiotropium) reduce the mean rate of COPD exacerbation [15, 63-65]. These effects have also been reported with combination therapy of inhaled corticosteroids and LABAs [66-69]. Furthermore, these studies have demonstrated that the reduction in exacerbations results in a significant decrease in hospitalisations and healthcare utilisation [63-69]. Other chronic therapies, such as carbocisteine and $\mathrm{N}$-acetylcysteine, showed a decrease in COPD exacerbations [70-73], while other studies failed to show these effects [74]. These findings could be explained by severity of patients enrolled in these studies and the use of concomitant medications. More detailed discussion is presented elsewhere in the present issue of the European Respiratory Review [75, 76].

\section{CONCLUSIONS}

Together, these studies demonstrate that exacerbations represent an important event in the natural history of COPD patients and are associated with significant morbidity and mortality. Though substantial progress has been made in the understanding of the aetiology of exacerbations in COPD, much still needs to be learned. The complexity of the hostpathogen interaction that determines the onset and course of exacerbations needs further exploration, including examination of host cellular and molecular mechanisms, and the determinants of pathogen virulence and their interaction with airway epithelial cells and macrophages. Exacerbations have a significant impact on patients' lung function, quality of life and exercise performance. Exacerbations are associated with increased morbidity and mortality and have a significant socioeconomic impact. Patients with frequent exacerbations often experience impaired quality of life and faster decline in lung function over time. In addition, exacerbations, including those requiring hospitalisation, are the largest item associated with the direct cost in the treatment of COPD.

\section{STATEMENT OF INTEREST}

A. Anzueto has been a consultant and paid speaker for the following companies: Boehringer-Ingelheim, GlaxoSmithKline, Dompé, Dey Pharmaceutical, Pfizer and Seprracor, and has been the principal 
investigator in clinical studies for which the University of Texas Health Science Center at San Antonio received funding from GlaxoSmithKline, Pfizer and Lilly.

\section{REFERENCES}

1 National Institutes of Health. National Heart, Lung, and Blood Institute. Morbidity and Mortality: 2002 Chart Book on Cardiovascular, Lung and Blood Diseases. Bethesda, National Heart, Lung, and Blood Institute, 2002. www.nhlbi.nih.gov/ resources/docs/02_chtbk.pdf Date last accessed: September 19, 2002.

2 Mannino DM, Homa DM, Akinbami LJ, et al. Chronic obstructive pulmonary disease surveillance - United States, 1971-2000. MMWR Surveill Summ 2002; 51: 1-16.

3 GOLD Executive and Science Committees. Global strategy for the diagnosis, management and prevention of chronic obstructive pulmonary disease: GOLD Executive Summary updated 2009. www.gold-copd.org Date last accessed: January 24, 2010.

4 Rabe KF, Hurd S, Anzueto A, et al. Global strategy for the diagnosis, management, and prevention of chronic obstructive pulmonary disease: GOLD executive summary. Am J Respir Crit Care Med 2007; 176: 532-555.

5 Miravitlles M, Murio C, Guerrero T, et al. Pharmacoeconomic evaluation of acute exacerbations of chronic bronchitis and COPD. Chest 2002; 121: 1449-1455.

6 Miravitlles M, Ferrer M, Pont A, et al. Effect of exacerbations on quality of life in patients with chronic obstructive pulmonary disease: a 2 year follow up study. Thorax 2004; 59: 387-395.

7 Halpern MT, Stanford RH, Borker R. The burden of COPD in the USA: results from the confronting COPD survey. Respir Med 2003; 97: Suppl. C, S81-S89.

8 Miravitlles M, Guerrero T, Mayordomo C, et al. Factors associated with increased risk of exacerbation and hospital admission in a cohort of ambulatory COPD patients: a multiple logistic regression analysis. The EOLO Study Group. Respiration 2000; 67: 495-501.

9 Burge PS, Calverley PMA, Jones PW, et al. Randomised, double blind, placebo-controlled study of fluticasone propionate in patients with moderate to severe chronic obstructive pulmonary disease: the ISOLDE trial. BMJ 2000; 20: 1297-1303.

10 Paggiaro PL, Dahle R, Bakran I, et al. Multicentre randomised placebo-controlled trial of inhaled fluticasone propionate in patients with chronic obstructive pulmonary disease. Lancet 1998; 351: 773-780.

11 Donaldson GC, Seemungal TAR, Bhowmik A, et al. Relationship between exacerbation frequency and lung function decline in chronic obstructive pulmonary disease. Thorax 2002; 57: 847-852.

12 Greenberg SB, Allen MA, Wilson J, et al. Respiratory viral infections in adults with and without chronic obstructive pulmonary disease. Am J Respir Crit Care Med 2000; 162: 167-173.

13 Miravitlles M, Mayordomo C, Artés M, et al. Treatment of chronic obstructive pulmonary disease and its exacerbations in general practice. EOLO Group. Observational de la Limitacion Obstructiva al Flujo aEreo. Respir Med 1999; 93: 173-179.

14 Gompertz S, Bayley DL, Hill SL, et al. Relationship between airway inflammation and the frequency of exacerbations in patients with smoking related COPD. Thorax 2001; 56: 36-41.

15 Decramer M, Celli B, Kesten S, et al. Effect of tiotropium on outcomes in patients with moderate chronic obstructive pulmonary disease (UPLIFT): a prespecified subgroup analysis of a randomized controlled trial. Lancet 2009; 374: 1171-1178.

16 Jenkins CR, Jones PW, Calverley PM, et al. Efficacy of salmeterol/ fluticasone propionate by GOLD stage of chronic obstructive pulmonary disease: analysis from the randomized, placebocontrolled TORCH study. Respir Res 2009; 10: 59.
17 Kosmas EN, Zorpidou D, Vassilareas V, et al. Decreased C4 complement component serum levels correlate with the degree of emphysema in patients with chronic bronchitis. Chest 1997; 112: 341-347.

18 Aaron SD, Vandemheen KL, Clinch JJ, et al. Measurment of shortterm changes in dyspnoea and disease-specific quality of life following an acute COPD exacerbation. Chest 2002; 121: 688-696.

19 Rutshmann OT, Cornuz J, Poletti PA, et al. Should pulmonary embolisms be suspected in exacerbation of chronic obstructive pulmonary disease? Thorax 2007; 62: 121-125.

20 Tillie-Leblond I, Marquette CH, Perez T. Pulmonary embolism in patients with unexplained exacerbation of chronic obstructive pulmonary disease: prevalence and risk factors. Ann Intern Med 2006; 144: 390-396.

21 Dewan NA, Rafique S, Kanwar B, et al. Acute exacerbation of COPD. Factors associated with poor outcome. Chest 2000; 117: 662-671.

22 Adams SG, Melo J, Luther M, et al. Antibiotics are associated with lower relapse rates in outpatients with acute exacerbations of COPD. Chest 2000; 117: 1345-1352.

23 Murata GH, Gorby MS, Kapsner CO, et al. A multivariate model for predicting hospital admissions for patients with decompensate chronic obstructive pulmonary disease. Arch Intern Med 1992; 152: 82-86.

24 Antonelli Incalzi R, Fuso L, De Rosa M, et al. Co-morbidity contributes to predict mortality of patients with chronic obstructive pulmonary disease. Eur Respir J 1997; 10: 2794-2800.

25 Vilkman S, Keistinen T, Tuuponen T, et al. Survival and cause of death among elderly chronic obstructive pulmonary disease patients after first admission to hospital. Respiration 1997; 64: 281-284.

26 Pinto-Plata VM, Mullerova H, Toso JF, et al. C-reactive protein in patients with COPD, control smokers and non-smokers. Thorax 2006; 61: 23-28.

27 Dahl M, Tybjaerg-Hansen A, Vestbo J, et al. Elevated plasma fibrinogen associated with reduced pulmonary function and increased risk of chronic obstructive pulmonary disease. Am J Respir Crit Care Med 2001; 164: 1008-1011.

28 Piehl-Aulin K, Jones I, Lindvall B, et al. Increased serum inflammatory markers in the absence of clinical and skeletal muscle inflammation in patients with chronic obstructive pulmonary disease. Respiration 2009; 78: 191-196.

29 Eagan TML, Ueland T, Wagner PD, et al. Systemic inflammatory markers in COPD: results from the Bergen COPD cohort study. Eur Respir J 2010; 35: 540-548.

30 Mortensen EM, Copeland LA, Pugh MJV, et al. Impact of statins and ACE inhibitors on mortality after COPD exacerbations. Respir Res 2009; 10: 45-54.

31 Anzueto A, Leimer I, Kesten S. Impact of frequency of COPD exacerbations on pulmonary function, health status and clinical outcomes. Int J Chron Obstruct Pulmon Dis 2009; 4: 245-251.

32 Spencer S, Jones PW, for the GLOBE Study Group, Time course of recovery of health status following an infective exacerbation of chronic bronchitis. Thorax 2003; 58: 589-593.

33 Spencer S, Calverley PMA, Burge S, et al. Health status deterioration in patients with chronic obstructive pulmonary disease. Am J Respir Crit Care Med 2001; 163: 122-128.

34 Donaldson GC, Wilkinson TM, Hurst JR, et al. Exacerbations and time spent outdoors in chronic obstructive pulmonary disease. Am J Respir Crit Care Med 2005; 171: 446-452.

35 Celli BR, Thomas NE, Anderson JA, et al. Effect of pharmacotherapy on rate of decline of lung function in chronic obstructive pulmonary disease. Am J Respir Crit Care Med 2008; 178: 332-338.

36 Connors AF Jr, Dawson NV, Thomas C, et al. Outcomes following acute exacerbation of severe chronic obstructive lung disease. The SUPPORT investigators (Study to Understand Prognoses and 
Preferences for Outcomes and Risks of Treatments). Am J Respir Crit Care Med 1996; 154: 959-967.

37 Seemungal TA, Donaldson GC, Bhowmik A, et al. Time course and recovery of exacerbations in patients with chronic obstructive pulmonary disease. Am J Respir Crit Care Med 2000; 161: 1608-1613.

38 Crooks SW, Bayley DL, Hill SL, et al. Bronchial inflammation in acute bacterial exacerbations of chronic bronchitis: the role of leukotriene B4. Eur Respir J 2000; 15: 274-280.

39 Ras G, Wilson R, Todd H, et al. The effect of bacterial products on neutrophil migration in vitro. Thorax 1990; 45: 276-280.

40 Stanescu D, Sanna A, Veriter C, et al. Airways obstruction, chronic expectoration, and rapid decline of FEV1 in smokers are associated with increased levels of sputum neutrophils. Thorax 1996; 51: 267-271.

41 Papi A, Bellettato CM, Braccioni F, et al. Infections and airway inflammation in chronic obstructive pulmonary disease severe exacerbations. Am J Respir Crit Care Med 2006; 173: 1114-1121.

42 Zhu J, Qiu YS, Majumdar S, et al. Exacerbations of bronchitis: bronchial eosinophilia and gene expression for interleukin-4, interleukin-5, and eosinophil chemoattractants. Am J Respir Crit Care Med 2001; 164: 109-116.

43 Sethi S, Muscarella K, Evans N, et al. Airway inflammation and etiology of acute exacerbations of chronic bronchitis. Chest 2000; 118: 1557-1565.

44 Viglio S, Iadarola P, Lupi A, et al. MEKC of desmosine and isodesmosine in urine of chronic destructive lung disease patients. Eur Respir J 2000; 15: 1039-1045.

45 Gompertz S, O'Brien C, Bayley DL, et al. Changes in bronchial inflammation during acute exacerbations of chronic bronchitis. Eur Respir J 2001; 17: 1112-1119.

46 Gottlieb DJ, Stone PJ, Sparrow D, et al. Urinary desmosine excretion in smokers with and without rapid decline of lung function: the Normative Aging Study. Am J Respir Crit Care Med 1996; 154: 1290-1295.

47 Andersson I, Johansson K, Larsson S, et al. Long-term oxygen therapy and quality of life in elderly patients hospitalised due to severe exacerbation of COPD. A 1 year follow-up study. Respir Med 2002; 96: 944-949.

48 Seemungal TAR, Donaldson GC, Paul EA, et al. Effect of exacerbations on quality of life in patients with chronic obstructive pulmonary disease. Am J Respir Crit Care Med 1998; 157: 1418-1422.

$49 \mathrm{Xu} \mathrm{W}$, Collet JP, Shapiro S, et al. Negative impact of unreported COPD exacerbations on health-related quality of life at 1 year. Eur Respir J 2010; 35: 1022-1030.

50 Garcia-Aymerich J, Lange P, Benet M, et al. Regular physical activity reduces hospital admission and mortality in chronic obstructive pulmonary disease: a population based cohort study. Thorax 2006; 61: 772-778.

51 Haughney J, Partridge MR, Vogelmeier C, et al. Exacerbations of COPD: quantifying the patient's perspective using discrete choice modelling. Eur Respir J 2005; 26: 623-629.

52 Kessler R, Stahl E, Vogelmeier C, et al. Patient understanding, detection and experience of COPD exacerbations. An observational, interview-based study. Chest 2006; 130: 133-142.

53 Hopkinson NS, Tennant RC, Dayer MJ, et al. A prospective study of decline in fat free mass and skeletal muscle strength in chronic obstructive pulmonary disease. Respir Res 2007; 8: 25.

54 Pitta F, Troosters T, Probst VS, et al. Physical activity and hospitalization for exacerbations of COPD. Chest 2006; 129: 536-544.

55 Cote C, Dordelly LJ, Celli BR. Impact of COPD exacerbations on patient-centered outcomes. Chest 2007; 131: 696-704.

56 Miravitlles M, Jardim JR, Zitto T, et al. Pharmacoeconomic study of antibiotic therapy for acute exacerbations of chronic bronchitis and chronic obstructive pulmonary disease. Arch Bronconeumol 2003; 39: 549-553.

57 Friedman M, Hilleman DE. Economic burden of chronic obstructive pulmonary disease. Pharmacoeconomics 2001; 19: 245-254.

58 Almagro P, Calbo E, Ochoa de Echaguen A, et al. Mortality after hospitalization for COPD. Chest 2002; 121: 1441-1448.

59 Groenewegen KH, Schols AM, Wouters EF. Mortality and mortality-related factors after hospitalization for acute exacerbation of COPD. Chest 2003; 124: 459-467.

60 Fuso L, Incalzi RA, Pistelli R, et al. Predicting mortality of patients hospitalized for acute exacerbated chronic obstructive pulmonary disease. Am J Med 1995; 98: 272-277.

61 Soler-Cataluna JJ, Martinez-Garcia MA, Roman Sanchez P, et al. Severe acute exacerbations and mortality in patients with chronic obstructive pulmonary disease. Thorax 2005; 60: 925-931.

62 Mahler DA, Donohue JF, Barbee RA, et al. Efficacy of salmeterol xinafoate in the treatment of COPD. Chest 1999; 15: 957-965.

63 Niewoehner DE, Rice K, Cote C, et al. Prevention of exacerbations of chronic obstructive pulmonary disease with tiotropium, a oncedaily inhaled anticholinergic bronchodilator: a randomized trial. Ann Internal Med 2005; 143: 317-326.

64 Dusser D, Bravo ML, Iacono P. The effect of tiotropium on exacerbations and airflow in patients with COPD. Eur Respir J 2006; 27: 547-555.

65 Tashkin DP, Celli B, Senn S, et al. A 4-year trial of tiotropium in chronic obstructive pulmonary disease. $N$ Engl J Med 2008; 359: 1543-1554.

66 Hanania NA, Darken P, Horstman D, et al. The efficacy and safety of fluticasone propionate $(250 \mu \mathrm{g}) /$ salmeterol $(50 \mu \mathrm{g})$ combined in the Diskus inhaler for the treatment of COPD. Chest 2003; 124: 834-843.

67 Calverley PM, Anderson JA, Celli B, et al. Salmeterol and fluticasone proprionate and survival in chronic obstructive pulmonary disease. N Engl J Med 2007; 356: 775-789.

68 Ferguson GT, Anzueto A, Fei R, et al. Effect of fluticasone propionate/salmeterol $(250 / 50 \mu \mathrm{g})$ or salmeterol $(50 \mu \mathrm{g})$ on COPD exacerbations. Respir Med 2008; 102: 1099-1108.

69 Anzueto A, Ferguson TG, Feldman G, et al. Effect of fluticasone propionate/salmeterol $(250 / 50)$ on COPD exacerbations and impact on patient outcomes. J COPD 2009; 6: 320-329.

70 Poole B, Black PM. Mucolytic agents for chronic bronchitis or chronic obstructive pulmonary disease. Cochrane Database Syst Rev 2010; 2: CD001287.

71 Stey C, Steurer J, Bachmann S, et al. Efficacy of oral $\mathrm{N}$ acetylcysteine in chronic bronchitis: a quantitative systematic review. Eur Respir J 2000; 16: 253-262.

72 Gramdjean EM, Berthet P, Ruffmann R, et al. Efficacy of oral longterm $\mathrm{N}$-acetylcysteine in chronic bronchopulmonary disease: a meta-analysis of published double-blind, placebo-controlled clinical trials. Clin Ther 2000; 22: 209-221.

73 Zheng JP, Kang J, Huang SG, et al. Effect of carbocisteine on acute exacerbation of chronic obstructive pulmonary disease (PEACE Study): a randomized placebo-controlled study. Lancet 2008; 371: 2013-2018.

74 Decramer M, Rutten-van MM, Dekhuijzen PN, et al. Effects of $N$ acetylcysteine on outcomes in chronic obstructive pulmonary disease (Bronchitis Randomized on NAC Cost-Utility Study, BRONCUS): a randomized placebo-controlled trial. Lancet 2005; 365: 1552-1560.

75 Miravitlles M. Prevention of exacerbations of COPD with pharmacotherapy. Eur Respir Rev 2010; 19: 119-126.

76 Decramer M, Janssens W. Mucoactive therapy in COPD. Eur Respir Rev 2010; 19: 134-140. 